\section{Deep vein thrombosis in children}

\author{
Kanakkande Aabideen, \\ Michael Ogendele, ljaz Ahmad, \\ Laweh Amegavie
}

Department of Pediatrics, Whiston Hospital, Whiston, Merseyside, UK

\begin{abstract}
We describe a rare case of deep vein thrombosis (DVT) in children, highlight the importance of early diagnosis of rare disease with potential complications. In a 5 year old boy presented with persistent leg pain without any obvious cause. Detailed investigation led to diagnosis of DVT. As there are common differential diagnoses for leg pain in children, pediatricians usually have a low index of suspicious of DVT in children. This case highlight that paediatricians must consider DVT in their differential diagnosis when children present with leg pain.
\end{abstract}

\section{Case Report}

A 5 year old Caucasian boy presented with one day history of painful left calf and refusal of walking. Two weeks previously, he had his 6 teeth extracted under general anesthesia. Since then he has been unwell and had episodes of fever. This was treated as infection with penicillin by his GP. During this period he has been drinking less fluid as compared to his usual intake. He has been less mobile for 3 days before he presented to us.

There was nothing significant in his past medical history. There was no significant hematological disease in his both parents' families. He has been fully immunized and had normal development and growth.

On examination, he was very irritable because of pain and all vital signs were normal. All peripheral pulses were well palpable. There was obvious swelling of the left calf with diameter of $25.5 \mathrm{~cm}$ as compared to right calf $(22.5 \mathrm{~cm})$. It was erythematous, hot, and severely tender on palpation. DVT was considered as differential diagnosis. Initial investigations showed normal Full Blood Count, CRP 6, and negative blood culture. Other blood investigation results include $\mathrm{Na} 138, \mathrm{~K} 4$, Urea 2.5, Creatinine 42 , blood sugar 5.8, Creatinine Kinase 64 and D Dimer more than 3000. In view of the high D Dimer and clinical presentation, Venography was performed and this confirmed the diagnosis of DVT of left popliteal vein. His abdominal Ultrasound as well as CT scan were normal. He was commenced on Enaxaparin $1.5 \mathrm{mg} / \mathrm{kg} / \mathrm{OD}$ by $\mathrm{S} / \mathrm{C}$, which was stopped on $9^{\text {th }}$ day with oral Warfarin started on $3^{\text {rd }}$ day with an aim to keep INR of between 2 and 3 . He was clinically improved; therefore he was discharged home on oral Warfarin. He is doing very well on follow-up. Currently he is off Warfarin after 6 months and his detailed thrombophilia screen was done which include prothrombin time $11.2 \mathrm{sec}(9-12)$, APTT $24 \mathrm{sec}$ (20-30), Fibrinogen $1 \mathrm{~g} / \mathrm{L}$ (1.5-4.5), thrombin time $21.4 \mathrm{sec}$ (15-22), Anticardiolipin IgG 3 GPL u/mL (0.0-11), Anticardiolipin IgM 5 MPL $\mathrm{u} / \mathrm{mL}$ (0-7), APTT for lupus $23 \mathrm{sec}$ (24-35) and Negative for Lupus Anticoagulant,. Factor V Leiden and Prothrombin Gene, Estimation of Protein $\mathrm{C}$ and $\mathrm{S}$ and antithrombin III level were normal.

\section{Discussion}

Deep Vein Thrombosis (DVT) is very rare in children. In the Canadian Registry, ${ }^{1}$ the incidence of DVT is 5.3/10,000 (0.05\%) hospital admissions or $0.07 / 10,000$ children with age between 1 month and 18 years old. Among these $96.4 \%$ cases have one or more associated conditions. These include cancer (22.6\%), congenital heart diseases (14.6\%), trauma (14.6\%), total parenteral nutrition (8\%), infection $(7.3 \%)$, nephrotic syndrome (5.8\%), surgery $(5.8 \%)$, birth control pills (5.1\%), obesity (2.9\%), sle (2.2\%), sickle cell anaemia (1.5\%) and liver failure (1.5\%). The same study showed that DVT without any associated condition is extremely rare $(1 / 51,000)$. Another prospective study in the Netherlands showed an incidence of $0.14 / 10,000$ children of same age group. In our patient; possible infection, dehydration and immobilization may have contributed to the development of DVT.2 However initial investigations did not show any evidence of infection or dehydration. We also did detailed investigation to find out the cause. But all came as normal. In our case D Dimer was more than 3000 which directed us to further investigation to establish DVT. The ELISAbased D-dimer estimation used as an excellent screening test in the evaluation of DVT in adults. ${ }^{3}$ However, this has been proved as an effective screening tool in children. ${ }^{4}$

There for we diagnosed it as Idiopathic DVT. We diagnosed DVT by venography as it was easily available investigation at the time in the hospital, although the lower extremities compression ultrasonography (sensitivity $91 \%$ and specificity $99 \%$ and MR venography (sensitivity $92 \%$ and specificity $95 \%$ ) have only been validated against the gold standard (contrast venography) in adults. ${ }^{5}$

As the incidence of DVT in children is
Correspondence: Kanakkande Aabideen, Department of Pediatrics, Whiston Hospital, Whiston, Merseyside, UK.

Tel. +44.772.5867054.

E-mail: abidcmc@yahoo.com

Key words: children, thrombosis, deep vein.

Conflict of interests: the authors declare no potential conflict of interests.

Received for publication: 30 August 2011. Revision received: 16 December 2011.

Accepted for publication: 16 December 2011.

This work is licensed under a Creative Commons Attribution NonCommercial 3.0 License (CC BYNC 3.0).

(C) Copyright K. Aabideen et al., 2013

Licensee PAGEPress, Italy

Pediatric Reports 2013; 5:e12

doi:10.4081/pr.2013.e12

extremely rare and there are other common differential diagnoses for leg pain in children, pediatricians usually have a low index of suspicion for DVT. This can lead to a delayed, or misdiagnosis of DVT in children. Case of a 6-yearold boy with fatal pulmonary embolism (PE) following DVT of the lower extremity vein has been reported. ${ }^{6}$ Interestingly, this case was initially diagnosed as irritable hip and pneumonia.

Pulmonary Embolism is a dreaded complication of DVT in adults and it has been reported in children. ${ }^{6}$ In Canadian Study PE was diagnosed in 22 children out of 33 children on the basis of a high probability V/Q scan. ${ }^{1}$ A study in the Netherlands showed one case of PE in 46 neonates with DVT, and 9 cases in 53 children of age between 1 month and 18 years. ${ }^{2}$ This highlights that, although the incidence of PE is less than in adult, this can occur in children. In our case there were no respiratory symptoms to suggest PE. Therefore we did not do V/Q scan. Current management practices of DVT in children are extrapolated from adult studies. However, the efficiency and tolerance of LMWH and Warfarin have been evaluated in children. ${ }^{7,8}$ Based on currently available best evidences,${ }^{9}$ the first line of treatment includes Heparin (UFH or LMWH) to prevent extension and oral anticoagulation to prevent recurrence. ${ }^{4}$

\section{Conclusions}

This case highlights that though the DVT is very rare in pediatric patients, it does occur. Pediatricians must consider DVT in their differential diagnosis when children present with leg pain. DVT is rare, but can be serious, and 
treatment guidelines validated in children are not available. There is a need for an evidencebased approach using information form International Registries.

\section{References}

1. Andrew M, David M, Adams M, et al. Venous thromboembolic complications (VTE) in children: first analyses of the Canadian Registry of VTE. Blood 1994;83: 1251-7.

2. van Ommen $\mathrm{CH}$, Heijboer $\mathrm{H}$, Buller $\mathrm{HR}$, et al. Venous thromboembolism in childhood: a prospective two-year registry in The Netherlands. J Pediatr 2001;139:676-81

3. Wells PS, Anderson DR, Rodger M, et al. Evaluation of D-dimer in the diagnosis of suspected deep-vein thrombosis. N Engl J Med 2003;349:1227-35.

4. Biss TT, Brandao LR, Kahr WH, et al. Clinical probability score and D-dimer estimation lack utility in the diagnosis of childhood pulmonary embolism. J Thromb Haemost 2009;7:1633-8.

5. Sampson FC, Goodacre SW, Thomas SM, van Beek EJ. The accuracy of MRI in diagnosis of suspected deep vein thrombosis: systematic review and meta-analysis. Eur Radiol 2007;17:175-81.
6. Sridhar AV, Rao NK, Chakraborty S. A sixyear old with fatal pulmonary embolism. Acta Paediatr 2005;94:977-9.

7. Tousovska K, Zapletal O, Skotakova J, et al. Treatment of deep venous thrombosis with low molecular weight heparin in pediatric cancer patients: safety and efficacy. Blood Coagul Fibrinolysis 2009;20:583-9.

8. Evans DI, Rowlands M, Poller L. Survey of oral anticoagulant treatment in children. J Clin Pathol 1992;45:707-8.

9. Brightwell RE, Osman IS. Iliofemoral deep vein thrombosis in childhood; developing a management protocol. Eur J Vasc Endovasc Surg 2006;31:667-78. 